\title{
The positive effect of Botulinum toxin type $A$ on the viability of random flap in tobacco exposed in rats ${ }^{1}$
}

\author{
Cristina Pires Camargo', Felipe Alexandre Fernandes ${ }^{\mathrm{II}}$, Michel Hyo Mi Lee ${ }^{\mathrm{II}}$, Luiza Campos Moreira Silva ${ }^{\mathrm{II}}$, Julio Morais \\ Besteiro $^{\text {III }}$, Rolf Gemperli ${ }^{\mathrm{IV}}$
}

DOI: http://dx.doi.org/10.1590/S0102-865020160110000003

IFellow PhD degree, Postgraduate Program in Surgical Clinics, Plastic Surgery Division, Faculty of Medicine, Universidade de São Paulo (FMUSP), Brazil. Scientific and intellectual content of the study, interpretation of data, critical revision.

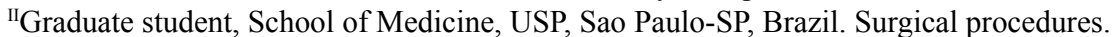

IIIPhD, Department of Plastic Surgery, FMUSP, Sao Paulo-SP, Brazil. Interpretation of data, critical revision.

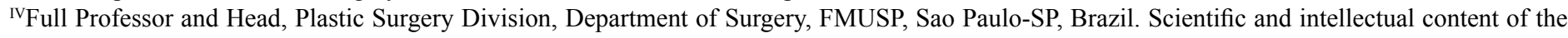
study, interpretation of data, critical revision.

\section{ABSTRACT}

PURPOSE: To evaluate the effect of Botulinum Toxin A in different time of tobacco exposure.

METHODS: 60 male, Wistar rats were divided into two tobacco exposure groups: a 2- month or a 4-month regimen. After this period, these two groups were subdivided as two: saline solution(SS) or botulinum toxin A(Bonta), at the time of the surgery. Seven days before the SS or Bonta injection, the animals were submitted to a random flap $(3 \times 10 \mathrm{~cm})$. On the seventh postoperative day, all animals were assessed for total flap area, viable area, and the viable/ total area ratio.

RESULTS: This study showed a difference between groups 2-month saline vs. BontA injection ( $p=0.04$ ); groups 4-month saline vs. BontA injection ( $\mathrm{p}=0.001)$; groups 2-month saline vs. 4-month BontA ( $\mathrm{p}=0.003)$, and, between groups 2- month BontA vs. 4-month saline $(\mathrm{p}=0.03)$.

CONCLUSIONS: Botulinum Toxin A increased random flap viability in tobacco-exposed rats. Two months of tobacco exposure had the same effect as exposure for four months.

Key words: Surgical Flaps. Botulinum Toxins, Type A. Survival. Tobacco. Rats. 


\section{Introduction}

Tobacco consumption is a global health problem; it is considered a pandemic involving 1.3 billion people. In Brazil, the prevalence of tobacco consumption is $14.7 \%$. Tobacco smoke was responsible for 6 million deaths per

One of the deleterious effects of smoking is wound healing complications.

Tobacco-exposure increases three times the rate of complications in wound Healing when Compared to a health patient $^{2,3}$.

For this reason, several strategies were studied to decrease surgical

complications $^{4-6}$, one of the strategies was to use BontA as a vasodilator ${ }^{7-9}$

We examined the effect of BontA in healthy rats, diabetic rats and, in rats exposed to smoke for 28-days, for the viability of skin flaps. Although BontA showed a difference in health and diabetic animals, there was no BontA effect in the flap viability for the tobacco-exposed group 9 . This hypothesis was based on other studies ${ }^{10,11}$. These studies showed a paradoxical increase of bronchodilation by using botulinum toxin type A (BontA) in a short time exposure to tobacco. Considering our previous study and the controversial results In the literature, we decided to test the effect of BontA in random flap for different smoke exposure periods.

\section{Methods}

The protocol was approved by the Ethics Committee of the Medical School, Universidade de São Paulo (028/2014). All procedures strictly followed current regulations related to animal experimentation dictated by the Council for International Organization of Medical Sciences, ethical code for animal experimentation. All animals were submitted to $24 \mathrm{~h}$ night/day cycles, water and chaw ad libitum.

Sixty Wistar rats were used, 2-month old, and weighing $250-300 \mathrm{~g}$. These animals were divided into two groups;

- 2-month smoke exposure regimes, Monday to Friday exposure, twice a day, 30 minutes/session;

- 4-month smoke exposure regimes, Monday to Friday exposure, twice a day, 30 minutes/session

Each group was subdivided as saline solution or BontA injection, seven days before the surgical procedure.

\section{Tobacco exposure}

The animals were exposed in a $28-\mathrm{L}$ plastic box with three orifices: on the inlet for synthetic air $(2 \mathrm{~L} / \mathrm{min})$; another for smoke; and, an outlet to ventilate the excessive smoke. The smoke inlet was connected to a Venturi system controlled by means of fluxometry $(2.5 \mathrm{~L} / \mathrm{min})$, which was connected to a lit cigarette.

Carbon monoxide $(\mathrm{CO})$ was monitored using a single gas detector (ToxiPro; Biosystems, USA) to maintain a CO concentration of 300-350 ppm (parts per million) inside the box.

At the end of the group exposure period, all animals were submitted to a random dorsal cutaneous flap $(3 \mathrm{x} 10 \mathrm{~cm})$.

\section{BontA/ saline solution injection}

Seven days before the surgical procedure, all animals were anesthetized with intraperitoneal ketamine $(100 \mathrm{mg} / \mathrm{Kg})$ and xylazine $(5 \mathrm{mg} / \mathrm{Kg})$. The torso was trichotomized and we designed a $3 \times 10 \mathrm{~cm}$ flap. According to the subgroup, we injected (intradermal) $0.02 \mathrm{ml}$ of BoNTA/puncture, a total of $20 \mathrm{u} / \mathrm{rat}$ $\left(\right.$ Botox $^{\circledR} 100 u$, Allergan. Irvine. CA. USA) or the same volume of saline solution. The puncture scheme was 2 rows of 10 puncture points (1cm apart).

\section{Surgical procedure}

Antisepsis was performed using $0.5 \%$ chlorhexidine. Under inhaled anesthesia ( $20 \%$ isoflurane; $150-200 \mathrm{ml} / \mathrm{min}$ ) the $3 \times 10 \mathrm{~cm}$ cranial flap based on the scapulae was elevated. The flap was then returned to its original position and sutured using separate stitches of 4-0 mononylon. Seven days after surgery, the rats were euthanized by anesthetic overdose (ketamine $200 \mathrm{mg} / \mathrm{kg}$ ).

\section{Flap area analysis}

Immediately before euthanasia the flaps were photographed (Olympus 3.5mm digital camera; Olympus Stylus ${ }^{\circledR}$, Japan) with a ruler along the length of the flap. The total area of the flap and the necrosis area were measured (squared millimeters) using the Image $J^{\circledR}$ software. The viable skin was defined as pink, warm, and soft to touch. Necrotic areas were defined as brown-toblack, cold, and hard to touch. Then we calculated the percentage of healthy skin area (Survival area). 


\section{Carboxyhemoglobin analysis}

At the end of the experiment, all animals were euthanized by anesthetic overdose (ketamine $200 \mathrm{mg} / \mathrm{kg}$ ).

Immediately after euthanize, we punctuated the heart of all animals for blood collection. We measured carboxyhemoglobin by $\mathrm{ABL}$ radiometer (Radiometer Medical Aps, BronshojDinamarca)

\section{Statistical analysis}

Performed descriptive statistics for data analysis with mean and standard deviation. We used the Kruskal- Wallis test and the Dunnet post hoc, for non- parametric data. We considered a p-value $<0.005$ and $80 \%$ power. We used STATA (StataCorp.2015.Stata Statistical Software: Release 14. College Station, TX:StataCorp LP)for all statistics analysis.

\section{Results}

Nine animals did not survive: five (two in group1, and three in group 4) died due to anesthesia; and four animals due to diarrhea (one in group 3 and three in group 2) (Table 1).

TABLE 1 - Comparison among total area, viable area, and ratio (viable area/total area) $\mathrm{mm}^{2}$.

\begin{tabular}{cccc}
\hline Group & Total area & Viable area & Ratio \\
\hline 1 & $2484.26 \pm 220.71$ & $1133.31 \pm 462.00$ & 0.44 \\
2 & $2277.205 \pm 196.43$ & $1389.96 \pm 320.37$ & 0.61 \\
3 & $2124.50 \pm 317.68$ & $1428.73 \pm 359.10$ & 0.59 \\
4 & $2401.32 \pm 387.69$ & $1644.94 \pm 393.80$ & 0.77 \\
\hline
\end{tabular}

The Kruskal -Wallis test showed difference among the groups $(p=0.07)$ and Dunn test showed a difference between group 1 and 2 (2-month saline versus BontA injection) $\mathrm{p}=0.04$; group3 and 4 (4-month saline versus BontA injection) $p=0.001$; group 1 and 4(2-month saline versus 4-month BontA) $\mathrm{p}=0.003$, and between group 2 and 3 (2-month BontA versus 4-month saline) $\mathrm{p}=0.03$ (Figure 1).

On the other hand, there was no difference between group 1 and 3 (2-month saline versus 4-month saline) $\mathrm{p}=0.43$ and, group 2 and 4 (2-month BontA versus 4-month BontA) p=0.16.

The overall carboxyhemoglobin seric concentration was $14.1 \%$ for all animals.

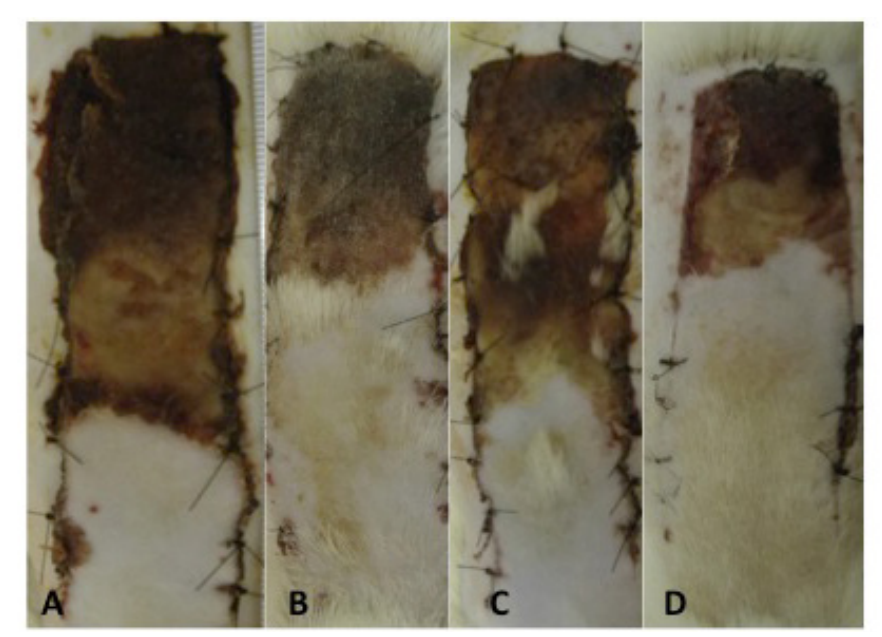

FIGURE 1 - Dorsal cutaneous flaps of rats at the day of euthanasia. A, 2-month tobacco exposure+saline; B, 2-month tobacco exposure +BoNTA; C, 4-month tobacco exposure+saline; D, 4-month tobacco exposure+BoNTA.

\section{Discussion}

One of our previous studies about the effect of BontA in diabetic, healthy and tobacco exposure on the cutaneous flap showed no vasodilation effect in 28 days of tobacco exposure for the BontA treatment group. This negative result guided us to reflect about this model being adequate for flap survival studies.

While searching for data in the literature, we identified studies about the paradoxical effect of tobacco in bronchiolar physiopathology. In a short period of tobacco-exposure the bronchia dilated but in a long-term exposure (more than 30days), the bronchia contracted. This piece of information suggested that we should test two- and four-month of tobacco exposure effect on the viability of cutaneous flap ${ }^{10,11}$.

Moreover, there was no difference in terms of flap viability between health (no exposure) and smoke-exposure animals in this previous study 9 . We hypothesized that the $3 \times 10 \mathrm{~cm}$ flap would cause a very severe vascular insufficiency resulting in necrosis, and that no additional deleterious environmental factor (tobacco-exposure) would increase necrosis. For this reason, we decided to inject a vasodilator (BontA), to evaluate the effect of two different time exposure regimens in flap viability.

According to our results, we showed that 2- and 4-month exposure regimens were adequate to produce vascular alterations that could benefit from vasodilator use (ratio $=0.61, \mathrm{p}=0.04$ and ratio $=0.71, \mathrm{p}=0.01$, respectively).

Additionally, there was no difference in flap viability for BontA groups related to exposure time (subgroups comparing 2 and 4months, $\mathrm{p}=0.16$ ). 
Comparing to literature data, most studies injected nicotine to evaluate strategies to improve flap viability. However, to reproduce a clinical condition, we believe that nicotine injection was inadequate. The cigarette had more than one thousand of substances that can interfere with flap survival, and for this reason we adopted this model $^{12}$.

Few exposure rat models were used in experimental studies. Nolan et $a l .{ }^{14}$, showed a mainstream exposure model. These authors exposed rats during a 28-day period and evaluated flap viability. The flap dimensions were $2.5 \times 10 \mathrm{~cm}$ and after 28 days of tobacco exposure, the necrosis was $78.2 \%$. Necrosis found in our study was different for several reasons; one reason was the flap dimensions $(2.5 \times 10 \mathrm{~cm}$ versus $3 \times 10 \mathrm{~cm})$. The other difference was the mainstream exposure regimen. Our model promotes an intermediate state of exposure between mainstream and side stream regimen. Carboxyhemoglobin measurement was also different, in Nolan et al. ${ }^{14}$ the carboxyhemoglobin level was $25 \%$, while in our project the carboxyhemoglobin level was $14.1 \%$. This last measure represented a moderate smoker patient ${ }^{15}$.

Moreover, it was difficult to reproduce the equipment used in Nolan et al. ${ }^{14}$, thus, we adopted the model of Biselli et al because it was a feasible and reproducible equipment ${ }^{12,14}$.

We consider these results methodological steps to define this tobacco exposure model as feasible and reproducible. Our study had some limitations; we did not assess the pathophysiology of tobacco smoke exposure. It would be important for next projects to study this outcome. Random cutaneous flap is routinely used in plastic surgery, but new studies must perform axial and composite flaps. More studies about pathophysiology and other therapeutic strategies should be done.

\section{Conclusions}

Botulinum Toxin A increased random flap viability in tobacco-exposed rats. Two months of tobacco exposure had the same effect as four months of exposure.

\section{References}

1. Asma S, Mackay J, Song SY, Zhao L, Morton J, Palipudi KM, et al. The GATS Atlas. Atlanta: CDC Foundation; 2015. Available from www. http://gatsatlas.org/cited.

2. Coon D, Tuffaha S, Christensen J, Bonawitz SC. Plastic surgery and smoking: a prospective analysis of incidence, compliance, and complications. Plast Reconstr Surg. 2013;131:385-91. PMID: 23358000 .

3. Gill JF, Yu SS, Neuhaus IM. Tobacco smoking and dermatologic surgery. J Am Acad Dermatol. 2013;68(1):167-72. PMID: 23103201.

4. Barral SM, Araujo ID, Vidigal PV, Mayrink CA, Araujo AC, Costa PR. Effects of sildenafil on the viability of random skin flaps. Acta Cir Bras. 2011;26(4):314-9. PMID: 4557709.
5. Lin DS, Zheng X, Li ZJ, Zhang YP, Wang AY, Xie XG, Gao WY. Effect of hirudin on random skin flap survival in rats. Zhonghua Zheng Xing Wai Ke Za Zhi. 2011;27(1):35-9. PMID: 21548386.

6. Oh M, Chang H, Minn KW. The effects of tadalafil on axial- pattern skin flap survival in rats. Dermatol Surg. 2008;34(5):626-30. PMID: 18261105.

7. Kim TK, Oh EJ, Chung JY, Park JW, Cho BC, Chung HY. The effects of botulinum toxin A on the survival of a random cutaneous flap. J Plast Aesthet Surg. 2009;62(7):906-13. PMID: 18436495.

8. Kim YS, Roh TS, Lee WJ, Yoo WM, Tark KC. The effect of botulinum toxin A on skin flap survival in rats. Wound Repair Regen. 2009;17(3):411-7. PMID: 19660050.

9. Camargo CP, JacomoAL, Battlehner CN, Lemos M, SaldivaPH, Martins MA, Munhoz AM, Gemperli R. Botulinum toxin type A on cutaneous flap viability in diabetic and tobacco-exposed rats. Acta Cir. Bras. 2015 Sep;30(9):639-45. doi: 10.1590/S0102865020150090000009.

10. Melgert BN, Postma DS, Geerlings M, Luinge MA, Klok PA, van der Strate BWA, Kerstjens HAM, Timens W, Hylkema MN Short-term smoke exposure attenuates ovalbumin-induced airway inflammation in allergic mice. Am J Respir Cell Mol Biol. 2004;30(6):880-5. doi: 10.1165/rcmb.2003-01780C.

11. Robbins CS, Pouladi MA, Fattouh R, Dawe DE, Vujicic N, Richards $\mathrm{CD}$, Jordana M, Inman MD, Stämpfli MR. Mainstream cigarette smoke exposure attenuates airway immune inflammatory responses to surrogate and common environmental allergens in mice, despite evidence of increased systemic sensitization. J Immunol. 2005;175(5):2832-42. PMID: 16116169.

12. Biselli PJC, Lopes FDTQS, Moriya HT, Rivero DH, Toledo AC Saldiva PH, Mauad T, Martins MA. Short-term exposure of mice to cigarette smoke and/or residual oil fly ash produces proximal airspace enlargements and airway epithelium remodeling. Braz J Med Biol Res. 2011;44(5):460-8. PMID: 21445523.

13. Cohen A, George O. Animal models of nicotine exposure: relevance to second-hand smoking, electronic cigarette use, and compulsive smoking. Front Psychiatry. 2013 Jun 4;4:41. doi: 10.3389/ fpsyt.2013.00041.

14. Nolan J, Jenkins RA, Kurihara K, Schultz RC. The acute effects of cigarette smoke exposure on experimental skin flaps. Plast Reconstr Surg. 1985;75(4):544-9. PMID: 3983255.

15. Gentry-Nielsen MJ, Top EV, Snilty MU, Casey CA, Preheim LC. Rat model to determine the biomedical consequences of concurrent ethanol ingestion and cigarette smoke exposure. Alcohol Clin Exp Res. 2004;28(7):1120-8. PMID: 15252300.

\section{Correspondence:}

Cristina Pires Camargo

Avenida Brigadeiro Luis Antonio, 4161

01402-002 São Paulo - Brasil

Tels.: (55 11)3884-7599 / 99182-3921

consultoriodracristina@gmail.com.br

Received: July 12, 2016

Review: Sep 14, 2016

Accepted: Oct 13, 2016

Conflict of interest: none

Financial source: none

${ }^{1}$ Research performed at Laboratory of Microsurgery and Plastic Surgery (LIM-04), Department of Surgery, Universidade de São Paulo (USP), Brazil. 